\title{
Dietary Antioxidant and Oxidative Stress: Interaction between Vitamins and Genetics
}

\author{
Aline Marcadenti ${ }^{*}$ and Raquel Cristina Lopes Assis Coelho ${ }^{2}$ \\ ${ }^{1}$ Department of Nutrition, Universidade Federal de Ciências da Saúde de Porto Alegre, Brazil \\ ${ }^{2}$ Department of Nutrition and Health, Federal University of Viçosa, Viçosa/MG, Brazil
}

Received: December 16, 2014; Accepted: March 18, 2015; Published: March 28, 2015

*Corresponding author: Aline Marcadenti, Department of Nutrition, Universidade Federal de Ciências da Saúd de Porto Alegre (UFSCPA), Porto Alegre, RS, 90050-170, Brazil, Tel: +55(51)33038830; Fax: +55(51)33038810; E-mail: marcadenti@yahoo.com.br

\begin{abstract}
Oxidative stress promotes DNA damage and may also contribute to the development of chronic disease, including type 2 diabetes (T2DM), neurodegenerative diseases, cardiovascular diseases and cancer. Oxidative stress is a result of an imbalance between the production and accumulation of reactive species and the organism's capacity to manage those using endogenous and exogenous antioxidants. Exogenous antioxidants obtained from the diet, mainly vitamin C, vitamin E, zinc, selenium and carotenoids have an important role in reducing oxidative stress and also DNA damage. Endogenous antioxidants include the enzymes catalase, glutathione peroxidase and superoxide dismutase. Nutrigenetics is a field of science that examines the interactions between diet and genetic variation. Individual genetic variation can affect proteins involved in the uptake, utilization and metabolism of dietary antioxidants. It may alter their serum levels and subsequent contribution to modulation of oxidative stress. The elucidation of interaction between genetic variations and antioxidant status may have important implications for public health through the identification of individuals and populations who could benefit from dietary intervention and supplementation with antioxidants. A greater understanding of which antioxidants could promote more protection and increase DNA repair may be important as a strategy to avoid the earlier development of chronic diseases.
\end{abstract}

Keywords: Antioxidants; Genetic variation; Nutrigenetics; Oxidative stress; Vitamins

\section{Introduction}

The great interest in the study of antioxidants is mainly due to the effects of free radicals in the organism. The oxidation process is essential to aerobic life. Thus, free radicals are naturally produced. However, these molecules react with DNA, RNA and other oxidizable substances, promoting damage. This may contribute to metabolic aging and degenerative diseases such as atherosclerosis and cancer $[1,2]$.

The excess of free radicals is neutralized by antioxidants produced in the organism (endogenous) or acquired from the diet (exogenous). Oxidative stress occurs as a result of an imbalance between the accumulation of reactive species and the organism's ability to neutralize them through endogenous and exogenous antioxidants [2].
Among the endogenous antioxidants are the enzymes: superoxide dismutase, catalase and glutathione peroxidase. These enzymes act on the metabolism of reactive species [1].

Dietary antioxidants such as vitamin C, vitamin E and carotenoids play an important role in prevention and reduction of oxidative stress. Epidemiologic studies have shown a negative correlation between regular consumption of fruits and vegetables and the prevalence of some degenerative diseases [3]. The protective effect exerted by these foods has been attributed to the presence of antioxidant compounds [1-3].

However, individual genetic variations can affect the components involved in the maintenance of oxidative balance. These variations are the subject of study of nutrigenetics. Polymorphisms in genes encoding antioxidant enzymes are associated with several types of cancer, although studies have shown controversial data [4]. This inconsistency may in part be explained by interactions with the environment, especially diet [5]. Habitual diet is able to modify the relationship between genetic variations in antioxidant enzymes and biomarkers of oxidative stress and thus affect the risk of developing disease $[3,4]$. Moreover, genetic variations affecting proteins involved in the metabolism, absorption, distribution, and elimination of exogenous antioxidants may influence exposure levels of antioxidants to target cells.

In this narrative review, we discuss concepts of oxidative stress, dietary antioxidants and also recent studies in the field of nutrigenetics and antioxidant intake as a strategy for DNA repair.

\section{Oxidative Stress}

The term free radical or reactive species is used to refer to any atom or molecule with an independent existence, containing one or more unpaired electrons in valence orbitals, whose highly reactive state may lead to damage by reaction with other cellular components.

Superoxide, hydroxyl, hydro peroxide, nitric oxide and nitrogen dioxide are examples of free radicals, which can cause DNA damage or oxidize lipids and proteins. Hydroxyl radical is the most reactive and can cause lesions in cellular molecules; as 
hydrogen peroxide, although it is not considered a free radical, is able to cross the nuclear membrane and to induce damage in the DNA molecule [6].

Reactive species, which can be oxygen (ROS) or nitrogen (RNS), are produced as a result of physiological processes and play roles in cell signaling, gene transcription and/or immune response. In aerobic metabolism, electron transport chain results in the production of superoxide anions. Other biological reactions, such as the role of phagocytes and cytochrome P450 enzymes also contribute to the formation of these highly reactive molecules. However, excess or accumulation of reactive species can cause damage to macromolecules, cell membranes and DNA [7].

The excess of free radicals can also be generated by exogenous factors, such as pollution, smoking or drinking alcohol, or by inadequate nutrition [8].

For this reason, there is a complex defense system to protect against over-production and possible damage caused by reactive oxygen species, contributing to the maintenance of "redox homeostasis" [1-3]. When the production or accumulation of free radicals exceeds the organism's ability to neutralize them, the state of oxidative stress arises [7,8].

In addition to direct damage to biological molecules and tissues, oxidative stress may also activate transcription factors such as nuclear factor $\kappa \mathrm{B}(\mathrm{NF}-\kappa \mathrm{B})$, which leads to activation of signaling cascades that culminate in the release of cytokines and inflammation [9].

Oxidative stress has been the subject of several studies in recent years, and has been associated with the pathogenesis of several chronic diseases, including cancer, T2DM, cardiovascular and neurodegenerative diseases [10-12]. This association was supported by several studies showing that diets rich in fruits and vegetables, so rich in dietary antioxidants are associated with reduced risk for chronic diseases $[3,4,13]$.

Antioxidants comprise a group of enzymes and components obtained from the diet, which protect against oxidative stress by neutralizing and preventing the formation of reactive species as well as repairing biological molecules $[7,4]$. The ability to protect against oxidative stress, therefore, depends on the integrity of endogenous and exogenous systems, and both can be influenced by genetic variations. Single Nucleotide Polymorphisms (SNPs) in genes encoding antioxidant enzymes or proteins involved in the uptake and utilization of dietary antioxidants may have a direct impact on the ability to handle oxidative stress [4]. In addition, endogenous and exogenous antioxidant systems interact, making it even more complex diet-gene interactions that result in the individual's ability to maintain "redox homeostasis" (Figure 1) [7].

\section{Antioxidants}

Antioxidants are substances present in low concentrations compared to oxidizable substrate that significantly retard or inhibit oxidation of that substrate [14]. Antioxidants act at different levels in the protection of organisms. The first defense mechanism against free radicals is to prevent their formation, primarily by the inhibition of chain reactions with iron and copper. Moreover, antioxidants are capable of intercepting the free radicals generated by cellular metabolism or exogenous sources, preventing the attack on lipids, amino acids and double bond of the polyunsaturated fatty acids and DNA bases, avoiding the formation of lesions and loss of cell integrity [7].

Thus, antioxidants may act directly or indirectly in the neutralization of free radicals. Antioxidant compounds are present both in organism and in food intake [8].

The primary enzymatic antioxidant defense system includes the enzymes superoxide dismutase, glutathione peroxidase and catalase. These substances can remove oxygen or highly reactive compounds reacting with the oxidizing compounds and protecting cells and tissues from oxidative stress [15]. Among the non-enzymatic components of antioxidant defense, we highlight some vitamins (vitamin C and vitamin E), phenolic compounds (flavonoids and phenolic acids) and carotenoids ( $\beta$-carotene and lycopene).

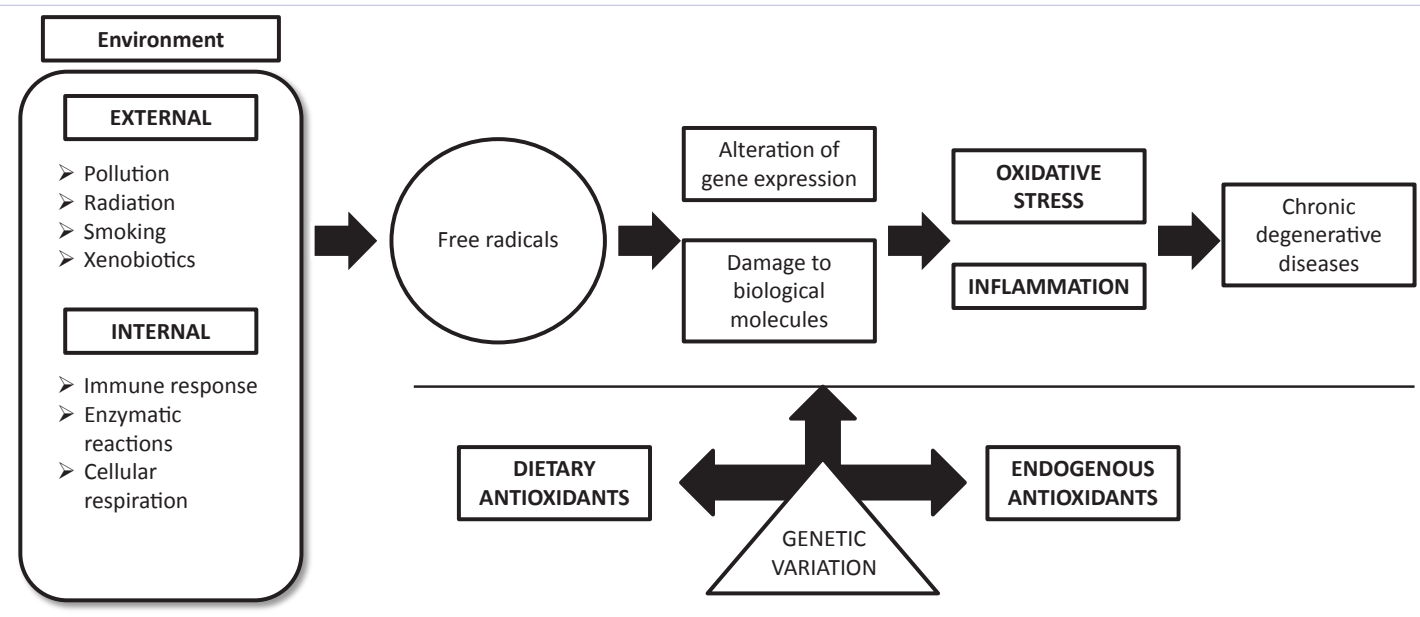

Figure 1: Overview of the relationship between the production of reative species, antioxidant defenses, oxidative stress, disease development and the role of antioxidants and genetic variation. 
Briefly, among the mechanisms responsible for the decrease of ROS are: a) catalytic removal of ROS by endogenous and exogenous antioxidants; b) binding proteins (transferrin, haptoglobins, ceruloplasmin) with pro-oxidant ions, such as iron and copper ions; c) protection against macromolecular damage stress proteins; d) reduction of free radicals by electron donors such as glutathione S-transferase, vitamin E (tocopherol), vitamin C (ascorbic acid), bilirubin and uric acid.

\section{Sources of Antioxidants}

Some nutrients and bioactive compounds acquired through diet have antioxidant functions and play an important role in the defense against oxidative stress (Table 1). These antioxidants work by preventing the formation of free radicals, neutralizing these already formed and repairing the damage caused by highly reactive molecules. Moreover, the antioxidants in the diet also interact with endogenous antioxidants, increasing the total antioxidant capacity [3]. Vitamin C is the primary water-soluble antioxidant, exerting their actions in the aqueous phase. In turn, vitamins $\mathrm{A}$ and $\mathrm{E}$ and carotenoids are soluble in lipids, acting mainly in cell membranes and lipoproteins. Although it primarily act on different phases (aqueous and lipid), these antioxidants can act together for regenerating the reduced form [16].

\section{Vitamin C}

Vitamin C is an essential nutrient and is the primary hydrophilic antioxidant in plasma. In addition to neutralizing free radicals, vitamin $\mathrm{C}$ also acts in the regeneration of $\alpha$-tocopherol, a component of the vitamin $\mathrm{E}$ family, which also has antioxidant action [17].

Vitamin C (ascorbic acid) is a white, crystalline, water-soluble and stable material in dry form. Its structure contains a hydroxyl group, the $\alpha$-hydroxyketone tautomer, which gives you not only reducing capability, but also an acid behavior. This vitamin is a derivative of hexose and classified as a carbohydrate, closely related to monosaccharides. The reduced form of ascorbic acid, which is most active, is rapidly oxidized to dehydroascorbic acid [1].

Most vitamin C (over 85\%) in the human diet is provided by citric fruits and vegetables. The ascorbic acid content in fruits and vegetables varies with the conditions under which they grow, and the degree of maturation [17]. Vitamin C consumed is absorbed in the small intestine by active transportation performed by the Vitamin C transporter type 1, which is encoded by the SLC23A1 gene (vitamin $\mathrm{C}$ transporter gene 1). This transporter is also

Table 1: Main exogenous antioxidants and their dietary sources.

\begin{tabular}{|l|l|}
\hline Dietary antioxidants & Sources \\
\hline Carotenoids & $\begin{array}{l}\text { Carrots, tomatoes, plums, apricots, } \\
\text { spinach, kale }\end{array}$ \\
\hline Vitamin C & $\begin{array}{l}\text { Kiwi, orange, strawberry, broccoli, } \\
\text { Brussels sprouts }\end{array}$ \\
\hline Vitamin E & Nuts, seeds, vegetable oil \\
\hline $\begin{array}{l}\text { Trace elements (zinc and } \\
\text { selenium) }\end{array}$ & Whole grains, seafood, meat \\
\hline
\end{tabular}

expressed in renal proximal tubules, where it operates in the reabsorption of ascorbate filtered in the glomeruli. The sodiumdependent vitamin C transporter type 2, encoded by the SLC23A2 gene is found in several tissues including brain, lung, liver and skeletal muscle [18].

\section{Vitamin E}

Vitamin E comprises a group of substances, including $\alpha, \beta, \gamma$ and $\delta$ tocopherols and $\alpha, \beta, \gamma$ and $\delta$ tocotrienols, with different biological activities. Vitamin $\mathrm{E}$ is an essential micronutrient consumed regularly in the diet from vegetable oils and derivatives, such as margarine. Additional dietary sources of vitamin E include meat and animal fat, whole grains, nuts and seeds [19].

The components of vitamin $\mathrm{E}$ in the duodenum are hydrolyzed by pancreatic lipases and incorporated in micelles. The carrier protein $\alpha$-tocopherol ( $\alpha$-TTP) incorporates $\alpha$-tocopherol to LDL molecules, which are released into the circulation for uptake in peripheral tissues. The $\alpha$-TPP is responsible for maintaining the levels of circulating $\alpha$-tocopherol far superior to other forms of vitamin E, although $\gamma$-tocopherol is the most abundant form of diet. Apparently, the intracellular transport of $\alpha$-tocopherol does not involve the $\alpha$-TTP, but other proteins [20].

Vitamin E has several functions in the organism, including membrane stabilization and regulation of the signaling cascade of gene expression, in addition to its known antioxidant properties. Their antioxidant activity is attributed to the chromanol ring, which has hydroxyl groups capable of donating electrons to ROS. The regeneration of $\alpha$-tocopherol may occur through redox reactions with vitamin $\mathrm{C}$, reduced glutathione and coenzyme $\mathrm{Q}$. As a fat-soluble molecule, the antioxidant actions of vitamin $\mathrm{E}$ are important in protection against membrane lipid peroxidation [19].

\section{Carotenoids}

Carotenoids are a large group (more than 600 natural carotenoids identified so far) of lipophilic substances. However, only about 60 of these carotenoids are normally found in the diet, and a small number have been isolated from human blood and tissue. The most abundant forms found in human plasma include $\alpha$-carotene, $\beta$-carotene, Lycopene and lutein [21].

Carotenoids print their characteristic color to many fruits and vegetables such as orange, carrots, and red tomatoes. These compounds can also be found in some plants of dark green leaves. The bioavailability of some carotenoids is significantly enhanced by boiling and addition of dietary fat [22].

Ingested and solubilized carotenoids are incorporated into micelles in the small intestine, and taken up by the mucosal cells. Traditionally, it was believed that the absorption of carotenoids was a passive process, but recent evidence suggests an active process. Absorbed carotenoids are incorporated into chylomicrons for clearing lymphatic circulation. Chylomicrons are taken up and metabolized by the liver in lipoproteins, which are the main source of circulating carotenoids [21]. 
The main functions described for carotenoids are related to their role as precursors of vitamin A. However, this applies only to carotenes and criptoxantines, since lycopene, lutein and zeaxanthin cannot be converted to retinol. Among the functions attributed to carotenoids, includes: inhibition of tumor growth, protection against genotoxicity and modulation of the immune system [22].

The antioxidant properties of carotenoids are particularly important in protecting lipids and can act in conjunction with vitamin $\mathrm{E}$ in preventing lipid peroxidation, being fat-soluble compounds. Carotenoids may also act to protect DNA against the action of free radicals and stimulating repair mechanisms [21].

\section{Antioxidants and Nutrigenetics}

Circulating concentrations of dietary antioxidants are influenced by many factors, including individual genetic variation. Genetic variations in absorption, metabolism, distribution and elimination of exogenous antioxidants may influence the exposure level of antioxidants to target cells [10]. Moreover, the diet interacts with the endogenous enzymes of the antioxidant system components, and hence the risk of chronic diseases.

\section{Genetic Determinants of Vitamin C Status}

Large interindividual variability was observed in circulating concentrations of ascorbic acid, as well as in response to vitamin C from the diet [23]. Environmental factors only partially explain the observed variability, and it was proposed that genetic variation could explain the differences in vitamin C concentrations between individuals. Accordingly, several variations to the status of vitamin $\mathrm{C}$ have been identified in several genes. A study with healthy young individuals of different ethnicities identified an association between variations in the SLC23A1 gene and circulating concentrations of ascorbic acid [24]. These findings were replicated later in a population of more than 15.000 individuals of European descent [25].

Polymorphisms in the SLC23A1 gene and changes in the glutathione S-transferase (GST) gene were also associated with the concentrations of ascorbic acid [26]. GST represents a family of enzymes that catalyze the reaction between glutathione and ROS resulting in the elimination of toxic metabolites.

\section{Genetic Determinants of Vitamin E Status}

Circulating concentrations of vitamin E, $\alpha$-tocopherol specifically, are used as markers of vitamin status. There are large variations between individuals in circulating levels of vitamin $\mathrm{E}$, and the correlation between intake and circulating concentrations was weak [27]. Approximately $22 \%$ of the variability found in the concentrations of $\alpha$-tocopherol was attributed to variations in key genes. One possible candidate is the APTT gene, which encodes the $\alpha$-TTP. In fact, a rare mutation in APTT was associated with the presence of ataxia and vitamin E deficiency, characterized by very low plasma concentrations of $\alpha$-tocopherol [28]. Genome-wide Association (GWAS) studies have indicated that genetic variants affecting the transport and metabolism of lipids are also important in determining the status of vitamin E [29].
Genetic variations can also be used to identify patients who would benefit from vitamin E supplementation in a specific population. Controlled studies of the effects of $\alpha$-tocopherol supplementation on cardiovascular risk factors studies have reported beneficial effects of supplementation, but limited to individuals who had a particular genotype of haptoglobin (Hp22). Among male smokers supplemented with $\alpha$-tocopherol (50 $\mathrm{mg} /$ day) for 3 years, polymorphisms (rs964184, rs2108622, rs7834588) were identified in three different loci (11q23.3, $8 \mathrm{q} 12.3$ and 19pter-p13.11) that, associated, accounted for $3.4 \%$ of the residual variation in serum vitamin E levels during supplementation [30]. For the future, it is expected that the supplements and food intake may be adequate based on the individual's genotype.

\section{Genetic Determinants of Carotenoids Status}

Considerable interindividual variability was reported in absorption, circulating concentration and response to supplementation of carotenoids, which can be explained by genetic variation [31]. As hydrophobic compounds, carotenoids are transported associated with lipoproteins in circulation. In fact, most attempts to identify genetic determinants of carotenoid status focused on genes involved in lipoprotein metabolism. Studies have identified several variations in the genes encoding proteins related to homeostasis of lipids and lipoproteins, including APOE, APOB, POEC 4, SRB-1 and hepatic lipase [9].

Two variations of BCM01 gene (beta-carotene $15,15^{\prime}$-monooxygenase 1), which encodes the $\beta$-carotene monooxygenase-1 were associated with circulating concentrations of $\beta$-carotene and the ability of this enzyme to convert $\beta$-carotene to vitamin A. Changes in the BCMO1 gene were associated with circulating concentrations of $\alpha$ and $\beta$ carotenes, lycopene, lutein and zeaxanthin. These results suggest that the variation of BCMO1 gene can affect the status of carotenoids and therefore the answer to supplement [32].

\section{Antioxidant Vitamins and DNA Repair}

The attack on DNA by ROS generates a variety of products. The hydroxyl radical, for example, may act on the DNA yielding single strand breaks and / or double-strand breaks, as well as lesions in the purine and pyrimidine bases, affecting the integrity of the genome [33].

In an attempt to demonstrate the antioxidant action of various compounds on the mechanisms of protection and repair from damage caused by accumulation of reactive species, studies with supplementation of vitamins (often at high doses) or diet rich in fruits and vegetables have been performed between different populations. Evidence, however, are inconclusive.

Randomized clinical trial among healthy subjects showed that compared to a drink with added sucrose (placebo) and supplemented with a vitamin C (150 mg), $300 \mathrm{ml}$ of orange juice (identical $150 \mathrm{mg}$ Vitamin C) reduced the damage to DNA from the mononuclear cells evaluated by the comet assay [34]. Another study among healthy adults who have used three different doses of vitamin C $(80,200$, or $400 \mathrm{mg})$ for 15 weeks 
concluded that there was no effect in reducing oxidative DNA damage after the intervention, suggesting that supplementation with vitamin $\mathrm{C}$ does not add benefits when an adequate amount of this antioxidant is obtained from dietary sources [35].

In another clinical trial, smokers subjects were randomized in two different interventions (supplementation of antioxidant vitamins in high doses: $250 \mathrm{mg}$ of vitamin C $2 \mathrm{x} /$ day or 250 mg of vitamin C $2 x /$ day $+91 \mathrm{Mg} 2 \mathrm{x} /$ day vitamin $\mathrm{E}$ ) or placebo showed that the addition of vitamins $C$ and $E$ prevented DNA damage. However, the high doses of supplementation were not enough to repair all the damage [determined by the expression of 8-oxoguanine DNA gene Glycosylase 1 (OGG1), associated with repair of oxidative damage in the molecule] [36]. Increased activity of OGG1 was associated in other studies with the consumption of vitamin C (only in the form of slow-release tablets), carrots, kiwi and eating a diet rich in fruits and vegetables [37].

In another study, healthy elderly subjects of different age groups were randomized for three groups: group A (placebo), group B (500 mg ascorbic acid and 400 IU of $\alpha$-tocopherol) or group C (1000 mg ascorbic acid and $400 \mathrm{IU} \alpha$-tocopherol). After six months, the supplementation of ascorbic acid and vitamin $\mathrm{E}$ in high amounts did not reduce oxidative stress (assessed by the concentration of superoxide dismutase, glutathione peroxidase, total antioxidant status and level of thiobarbituric acid reactive substances) and the damage in DNA rated by comet assay [38].

Among individuals with type 2 diabetes mellitus who were randomized to receive placebo or $1200 \mathrm{IU} /$ day of $\alpha$-tocopherol for 4 weeks, there was no significant difference at the end of the study in relation to oxidative DNA damage in mononuclear cells. Among patients supplemented with $\alpha$-tocopherol, oxidative DNA damage was increased after performing oral glucose tolerance test (OGTT) [39].

Patients at risk of gastric cancer were randomized to the placebo group or antioxidant supplementation group (vitamin C: $2 \mathrm{x} /$ day $500 \mathrm{mg}+$ Vitamin E: $100 \mathrm{mg} 2 \mathrm{x} /$ day) for 12 weeks, and there was no significant difference between the two groups in relation to DNA damage assessed by comet assay, nor on the concentration of malondialdehyde (MDA, a marker of oxidative stress [40].

Antioxidant activity of vitamin $\mathrm{C}$ and vitamin $\mathrm{E}$ was also found in cell culture through comet assay. After pre-incubation of human tumor cells with vitamin $\mathrm{C}$, the antioxidant in high doses (200 mM) taken into the interior of these cells was not enough to stabilize the DNA and prevent the damage caused by sun exposure or contact with hydrogen peroxide. When 4-hydroxyestradiol [4-OHE(2), an abnormal cell growth promoter] was added to a culture of human mammary epithelial cells which were incubated for $96 \mathrm{~h}$ with and without the addition of tocopherol, antioxidant reduced oxidative stress by scavenging of reactive oxygen species and also promoted the increased gene expression of elements of DNA repair [41].

Controlled study was conducted among well-nourished individuals who took daily $600 \mathrm{~g}$ of fruit and vegetables (or the equivalent in antioxidants vitamins in the form of supplementation) and malnourished individuals smokers who ingested $500 \mathrm{mg}$ vitamin $\mathrm{C}$ in the form of supplementation (or vitamin $\mathrm{C}$ added to $182 \mathrm{~g}$ of vitamin $\mathrm{E}$ ) in capsules of fast or slow release. The results showed that only smokers with impaired nutritional status and who used slow-release capsules of vitamin $\mathrm{C}$ reduced the levels of oxidation in DNA of mononuclear cells, as well as increased repair activities in the molecule [42]. It is suggested that nutritional status, prior level of DNA damage and the ability to repair are interconnected and that supplementation has a beneficial effect only among people with weakened nutritional status or low serum antioxidant levels, lower baseline levels of repair activity and prior high level of oxidative DNA damage.

The vitamin C supplementation reduced the frequency of chromosomal aberrations among individuals with insufficient intake of this antioxidant and exposed to mutagenic factors; vitamin $\mathrm{C}$ also decreased the sensitivity for these mutagenic agents like bleomycin chemotherapy. The modulation in DNA repair by supplementation was observed in healthy individuals and also in malnourished patients with plasma vitamin C levels > $50 \mu \mathrm{mol} / \mathrm{l}$ exposed to high concentrations of Polycyclic Aromatic Hydrocarbons (PAHs), reinforcing the hypothesis that the effects of vitamin $\mathrm{C}$ on the damage in the DNA depends both basal serum values of vitamin $\mathrm{C}$ as the level of exposure to exogenous oxidative stress inducers [43].

Epigenetics may explain the correlations between lifestyle and risk for developing a number of chronic diseases, and maternal diet has been shown to be highly dynamic in the regulation of epigenetic mechanisms, including affecting the methylation status of DNA. Rats with vitamin A deficiency in the diet during pregnancy had the level of methylation in gene GATA binding protein 4 (GATA-4, involved in embryogenesis and in the differentiation and function of myocardial cells) reported in the offspring; after dissection of embryo heart during cardiac maturation, high levels of methylation in GATA gene and increased incidence of heart defects were found [44].

Newborn rats received vitamin A supplementation in an amount three times the yield of breast milk, and were compared with a control group that received supplementation of olive oil. After weaning, the animals supplemented with vitamin A were exposed to a high-fat diet or a low-fat diet. The subcutaneous adipose tissue of animals supplemented with the antioxidant, reported soon after weaning, was full of small adipocytes with reduced gene expression of adipogenic markers [lipoprotein lipase and peroxisome proliferator-activated receptor $\gamma$ (PPARgamma)] and increased potential for proliferation. The animals supplemented with vitamin A developed greater adiposity hyperplasia compared to the control group after the intervention fat diet, detected by analysis of body composition (increased mass of subcutaneous adipose tissue), diameter of adipocytes, presence of leptin and increased expression of LEP gene in adipose tissue. In this study, it was concluded that, in animal models, vitamin A supplementation in the early stages of postnatal life favored fat diet induced adiposity, through mechanisms that may be related to changes in adipose tissue development [45]. 
The role of dietary antioxidants on the individual variation in the ability to defend against oxidative stress on the system and repair of oxidative DNA damage has been reported among patients with and without pancreatic cancer, in a study of the case-control type. Individuals homozygous for the wild allele in Ala16Val (rs4880) polymorphism in superoxide dismutase 2 gene (SOD2) showed increased risk of cancer compared to carriers of the variant allele, and the protective effect of the Val allele was more pronounced, interestingly, among individuals who had intake of antioxidants (lycopene, $\alpha$-carotene and $\alpha$-tocopherol) below the median [46].

Randomized clinical trials have failed to demonstrate associations between supplementation of high doses of antioxidants in the prevention of severe outcomes, such as acute myocardial infarction and mortality. Meta-analysis developed by the Cochrane group, which evaluated the effect of supplementing a number of antioxidants (beta-carotene, vitamin A, vitamin E, vitamin $\mathrm{C}$ and selenium) versus placebo or no intervention in well-designed randomized clinical trials $(296,707$ participants in total) concluded that there is no evidence to support the supplementation of vitamins and antioxidants in the prevention of mortality in primary and secondary level (beta-carotene, vitamin a and vitamin $\mathrm{E}$ in high doses, were even associated with increased mortality) [47].

\section{Conclusion}

Oxidative stress has been implicated in the development of chronic diseases. Diets with a high consumption of fruits and vegetables (rich in antioxidants) tend to be inversely related to the development and progression of cardiovascular and metabolic diseases. However, clinical trials involving supplementation of antioxidants proved extremely controversial results, and few side effects were reported. Genetic variations involving the uptake, distribution, metabolism and transport of dietary antioxidants were associated with changes in circulating concentrations of antioxidants and hence different responses to supplementation. Therefore, genetic variations may help explain some of the controversies found in the studies. In addition, genetic variations may modulate the relationship between the endogenous enzymatic antioxidant system and environmental factors such as antioxidants acquired by the diet.

Finally, the elucidation of the genetic variations and antioxidant status may have important implications for public health through the identification of individuals and populations that would benefit most from dietary intervention and supplementation with antioxidants.

\section{References}

1. Prior RL, Cao G, Prior RL, Cao G. Analysis of botanicals and dietary supplements for antioxidant capacity: a review. J AOAC Int. 2000; 83(4):950-6.

2. Halliwell B. Oxidative stress and cancer: have we moved forward? Biochem J. 2007; 401(1): 1-11.

3. Da Costa LA, García-Bailo B, Badawi A, El-Sohemy A. Genetic determinants of dietary antioxidant status. Prog Mol Biol Transl Sci. 2012; 108: 179-200. doi: 10.1016/B978-0-12-398397-8.00008-3.
4. Da Costa LA, Badawi A, El-Sohemy A. Nutrigenetics and modulation of oxidative stress. Ann Nutr Metab. 2012; 60 Suppl 3: 27-36. doi: 10.1159/000337311.

5. Serafini M. The role of antioxidants in disease prevention. Medicine. 2006; 34(12): 533-35.

6. Valko M, Leibfritz D, Moncol J, Cronin MTD, Mazur M, Telser J. Free radicals and antioxidants in normal physiological functions and human disease. Int J Biochem Cell Biol. 2007; 39(1): 44-84.

7. Møller P, Loft S. Oxidative DNA damage in human white blood cells in dietary antioxidant intervention studies. Am J Clin Nutr. 2002; 76(2): 303-10.

8. Barbosa KBF, Costa NMB, Alfenas RCG, De Paula SO, Minim VPR, Bressan J. Oxidative stress: concepts, implications and modulatory factors. Rev Nutr. 2010; 23(4): 629-43.

9. Hotamisligil GS. Inflammation and metabolic disorders. Nature. 2006; 444(7121): 860-7.

10. Stephens JW, Khanolkar MP, Bain SC. The biological relevance and measurement of plasma markers of oxidative stress in diabetes and cardiovascular disease. Atherosclerosis. 2009; 202(2): 321-9. doi: 10.1016/j.atherosclerosis.2008.06.006.

11. Uttara B, Singh AV, Zamboni P, Mahajan RT. Oxidative stress and neurodegenerative diseases: a review of upstream and downstream antioxidant therapeutic options. Curr Neuropharmacol. 2009; 7(1): 65-74. doi: 10.2174/157015909787602823.

12.Valko M, Rhodes CJ, Moncol J, Izakovic M, Mazur M. Free radicals, metals and antioxidants in oxidative stress-induced cancer. Chem Biol Interact. 2006; 160(1): 1-40.

13. Halliwell B. Oxidative stress and neurodegeneration: where are we now? J Neurochem. 2006; 97(6): 1634-58.

14. Ferrari CK. Functional foods, herbs and nutraceuticals: towards biochemical mechanisms of healthy aging. Biogerontology. 2004; 5(5): 275-289.

15. Giustarini D, Dalle-Donne I, Tsikas D, Rossi R. Oxidative stress and human diseases: origin, link, measurement, mechanisms, and biomarkers. Crit Rev Clin Lab Sci. 2009; 46(5-6): 241-81. doi: $10.3109 / 10408360903142326$.

16. García-Bailo B, El-Sohemy A, Haddad P, Arora P, Benzaied F, Karmali $\mathrm{M}$, et al. Vitamins $\mathrm{D}, \mathrm{C}$, and $\mathrm{E}$ in the prevention of type 2 diabetes mellitus: modulation of inflammation and oxidative stress. Biologics. 2011; 5: 7-19. doi: 10.2147/BTT.S14417.

17. Azqueta A, Costa S, Lorenzo Y, Bastani NE, Collins AR. Vitamin C in cultured human (HeLa) cells: lack of effect on DNA protection and repair. Nutrients. 2013; 5(4): 1200-17. doi: 10.3390/nu5041200.

18. Tsukaguchi H, Tokui T, Mackenzle B, Berger UV, Chen XZ, Wang Y, et al. A family of mammalian $\mathrm{Na}^{+}$-dependent L-ascorbic acid transporters. Nature. 1999; 399(6731): 70-5.

19. Schneider C. Chemistry and biology of vitamin E. Mol Nutr Food Res. 2005; 49(1): 7-30.

20. Anwar K, Iqbal J, Hussain MM. Mechanisms involved in vitamin E transport by primary enterocytes and in vivo absorption. J Lipid Res. 2007; 48(9): 2028-38.

21. Yonekura L, Nagao A. Intestinal absorption of dietary carotenoids. Mol Nutr Food Res. 2007; 51(1): 107-15.

22. Olson JA, Krinsky NI. Introduction: the colorful, fascinating world of 
the carotenoids: important physiologic modulators. FASEB J. 1995; 9(15): 1547-50.

23. Loria CM, Whelton PK, Caulfield LE, Szklo M, Klag MJ. Agreement among indicators of vitamin C status. Am J Epidemiol. 1998; 147(6): 587-96.

24. Cahill LE, El-Sohemy A. Vitamin C transporter gene polymorphisms, dietary vitamin $\mathrm{C}$ and serum ascorbic acid. J Nutrigenet Nutrigenomics. 2009; 2(6): 292-301. doi: 10.1159/000314597.

25. Timpson NJ, Forouhi NG, Brion MJ, Harbord RM, Cook DG, Johnson $\mathrm{P}$, et al. Genetic variation at the SLC23A1 locus is associated with circulating concentrations of $\mathrm{L}$-ascorbic acid (vitamin $\mathrm{C}$ ): evidence from 5 independent studies with $>15,000$ participants. Am J Clin Nutr. 2010; 92(2): 375-82. doi: 10.3945/ajcn.2010.29438.

26. Horska A, Mislanova C, Bonassi S, Ceppi M, Volkovova K, Dusinska M. Vitamin $C$ levels in blood are influenced by polymorphisms in glutathione S-transferases. Eur J Clin Nutr. 2011; 50(6): 437-46. doi: 10.1007/s00394-010-0147-2.

27. Roxborough HE, Burton GW, Kelly FJ. Inter and intra-individual variation in plasma and red blood cell vitamin $\mathrm{E}$ after supplementation. Free Radic Res. 2000; 33(4): 437-45.

28. Gueguen S, Leroy P, Gueguen R, Siest G, Visvikis S, Herbeth B. Genetic and environmental contributions to serum retinol anda-tocopherol concentrations: the Stanislas Family Study. Am J Clin Nutr. 2005; 81(5): 1034-44.

29. Major JM, Yu K, Wheeler W, Zhang H, Cornelis MC, Wright ME, et al. Genome-wide association study identifies common variants associated with circulating vitamin E levels. Hum Mol Genet. 2011; 20(19): 3876-83. doi: 10.1093/hmg/ddr296.

30. Farbstein D, Blum S, Pollak M, Asaf R, Viener HL, Lache O, et al. Vitamin E therapy results in a reduction in HDL function in individuals with diabetes and the haptoglobin 2-1 genotype. Atherosclerosis. 2011; 219(1): 240-4. doi: 10.1016/j.atherosclerosis.2011.06.005.

31. Zhao X, Aldini G, Johnson EJ, Rasmussen H, Kraemer K, Woolf $\mathrm{H}$, et al. Modification of lymphocyte DNA damage by carotenoid supplementation in postmenopausal women. Am J Clin Nutr. 2006; 83(1): 163-9.

32. Borel P, De Edelenyi FS, Vincent-Baudry S, Malezet-Desmoulin C, Margotat A, Lyan B, et al. Genetic variants in BCMO1 and CD36 are associated with plasma lutein concentrations and macular pigment optical density in humans. Ann Med. 2011; 43(1): 47-59. doi: 10.3109/07853890.2010.531757.

33. Aruoma OI. Free radicals, oxidative stress, and antioxidants in human health and disease. J Am Oil Chem Soc. 1998; 75(2): 199-212.

34. Guarnieri S, Riso P, Porrini M. Orange juice vs vitamin C: effect on hydrogen peroxide-induced DNA damage in mononuclear blood cells. Br J Nutr. 2007; 97(4): 639-43.

35. Herbert KE, Fletcher S, Chauhan D, Ladapo A, Nirwan J, Munson S, et al. Dietary supplementation with different vitamin $C$ doses: no effect on oxidative DNA damage in healthy people. Eur J Nutr. 2006; 45(2): 97-104.

36. Møller P, Viscovich M, Lykkesfeldt J, Loft S, Jensen A, Poulsen HE. Vitamin C supplementation decreases oxidative DNA damage in mononuclear blood cells of smokers. Eur J Nutr. 2004; 43(5): 267-74.

37. Collins AR, Azqueta A, Langie SA. Effects of micronutrients on DNA repair. Eur J Nutr. 2012; 51(3): 261-79. doi: 10.1007/s00394-0120318-4.

38. Retana-Ugalde R, Casanueva E, Altamirano-Lozano M, GonzálezTorres C, Mendoza-Núñez VM. High dosage of ascorbic acid and alphatocopherol is not useful for diminishing oxidative stress and DNA damage in healthy elderly adults. Ann Nutr Metab. 2008; 52(2): 16773. doi: $10.1159 / 000129652$

39. Winterbone MS, Sampson MJ, Saha S, Hughes JC, Hughes DA. Prooxidant effect of alpha-tocopherol in patients with type 2 diabetes after an oral glucose tolerance test: a randomized controlled trial. Cardiovasc Diabetol. 2007; 6: 8-17.

40. White KL, Chalmers DM, Martin IG, Everett SM, Neville PM, Naylor G, et al. Dietary antioxidants and DNA damage in patients on long-term acid-suppression therapy: a randomized controlled study. Br J Nutr. 2002; 88(3): 265-71.

41. Lee EJ, Oh SY, Kim MK, Ahn SH, Son BH, Sung MK. Modulatory effects of alpha- and gamma-tocopherols on 4-hydroxyestradiol induced oxidative stresses in MCF-10A breast epithelial cells. Nutr Res Pract. 2009; 3(3): 185-91. doi: 10.4162/nrp.2009.3.3.185.

42. Guarnieri S, Loft S, Riso P, Porrini M, Risom L, Poulsen HE, et al. DNA repair phenotype and dietary antioxidant supplementation. Br J Nutr. 2008; 99(5): 1018-24.

43. Sram RJ, Binkova B, Rossner P Jr. Vitamin C for DNA damage prevention. Mutat Res. 2012; 733(1-2): 39-49. doi: 10.1016/j. mrfmmm.2011.12.001.

44. Feng Y, Zhao LZ, Hong L, Shan C, Shi W, Cai W. Alteration in methylation pattern of GATA-4 promoter region in vitamin A-deficient offspring's heart. J Nutr Biochem. 2013; 24(7): 1373-80. doi: 10.1016/j. jnutbio.2012.11.005.

45. Granados N, Amengual J, Ribot J, Musinovic H, Ceresi E, von Lintig J, et al. Vitamin A supplementation in early life affects later response to an obesogenic diet in rats. Int J Obes (Lond). 2013; 37(9): 1169-76. doi: 10.1038/ijo.2012.190.

46.Zhang J, Zhang X, Dhakal IB, Gross MD, Kadlubar FF, Anderson KE. Sequence variants in antioxidant defense and DNA repair genes, dietary antioxidants, and pancreatic cancer risk. Int J Mol Epidemiol Genet. 2011; 2(3): 236-244.

47. Bjelakovic G, Nikolova D, Gluud LL, Simonetti RG, Gluud C. Antioxidant supplements for prevention of mortality in healthy participants and patients with various diseases. Cochrane Database Syst Rev. 2012; 3: CD007176. doi: 10.1002/14651858.CD007176.pub2. 